\title{
A epistemologia de Gaston Bachelard: uma ruptura com as filosofias do imobilismo*
}

\author{
Marcos Antonio Martins Lima ${ }^{1}$ \\ Marcos Marinelli ${ }^{2}$ \\ Universidade Federal do Ceará
}

Este artigo analisa algumas das obras de Gaston Bachelard, expondo as articulações essenciais do pensamento de Bachelard, apresentando as idéias centrais de sua epistemologia. Apresenta críticas de Bachelard a algumas perspectivas epistemológicas que predominavam no momento em que surgem suas obras, descrevendo as diferenças entre as mesmas (senso comum de Émile Meyerson; doutrina espiritualista de Maine de Biran; e o positivismo de Auguste Comte). Descreve os principais conceitos da epistemologia bachelardiana - ruptura, vigilância, obstáculo, problemática e recorrência epistemológica. Aborda a visão de Bachelard da educação como formação e reforma, constatando-se sua profunda vocação pedagógica. Foi utilizada como metodologia a revisão bibliográfica, mesclando autores nacionais e internacionais, clássicos e contemporâneos. Conclui apontando que a epistemologia bachelardiana está presente e atuante no meio científico, apresentando contribuições significativas.

Palavras-chaves: Epistemologia - Epistemologia Bachelardiana-Gaston Bachelard.
This article examines some intellectual contributions by Gaston Bachelard, exposing their essential joints thoughts, introducing the central ideas of his epistemology. Bachelard presents some criticisms of epistemological perspectives that prevailed at the time he drew the works, describing the differences between them (common sense of Emile Meyerson; spiritual doctrine of Maine de Biran, and the positivism of Auguste Comte). Describes the main concepts of Bachelardian epistemology - rupture, surveillance, obstruction, recurrence and epistemological problems. Bachelard discusses the view of education as training and reform, noting his deep educational vocation. The literature review was the methodology used, mixing national and international authors, classic and contemporary. It concludes by pointing out that the Bachelardian epistemology is present and active at scientific circles, with significant contributions.

Keywords: Epistemology - Bachelardian epistemology - Gaston Bachelard.

\footnotetext{
* The epistemology of Gaston Bachelard: a break with the immobility philosophies.

${ }^{1}$ Professor Adjunto. Programas de Pós-Graduação em Educação (FACED/UFC) e Administração e Controladoria (FEAAC/UFC), da Universidade Federal do Ceará. Endereço para correspondências: Rua Almeida Prado, 1250, apto. 600, Fortaleza, Ceará,60176-050 (marcos.a.lima@terra.com.br ou marcoslima@ufc.br).

${ }^{2}$ Doutorando em Educação. Programa de Pós-Graduação em Educação (FACED/UFC) e Faculdade de Psicologia e de Ciências da Educação (Universidade de Coimbra). Endereço para correspondências: Rua Inglaterra, 150, Casa 7, Parangaba, Fortaleza, Ceará, 60710-060 (marinelli_marcos@hotmail.com).
} 


\title{
HUMANAS
}

\section{Introdução}

\begin{abstract}
A epistemologia bachelardiana inaugura a filosofia do inexato, na qual o conhecimento constitui-se por meio de aproximações contínuas, viabilizadas, simultaneamente, pelo conhecimento teórico e pela aplicação técnica. O objeto não é mais dado, mas construído. Havendo, dessa forma, uma supremacia do conhecimento abstrato e científico sobre o conhecimento primeiro e intuitivo (BACHELARD, 1996).

A obra bachelardiana defende uma polaridade epistemológica, mostrando que, para se adequar à ciência atual, a filosofia das ciências deve ser uma filosofia de dois pólos: realista e idealista, empirista e racionalista, ao mesmo tempo. Não significa um dualismo, mas sim, o reconhecimento de que a alternância do a priori e do a posteriori representa a própria dinâmica do conhecimento e que esses pólos, em lugar de se oporem, completam-se, oferecendo à ciência o seu verdadeiro dinamismo.

Este artigo se propõe a analisar as idéias centrais da obra epistemológica de Gaston Bachelard, notadamente sua concepção de ruptura, vigilância, obstáculos epistemológicos, problemática e recorrência, na construção do novo espírito científico, em contraposição às filosofias do imobilismo.

Para além de filósofo, crítico e epistemologista, Bachelard era cientista e poeta. A publicação de suas obras revela essa oscilação de interesses: a Filosofia das Ciências, a Lógica, a Psicologia e a poesia. Seus trabalhos no domínio da epistemologia continuam a ter grande relevância para a compreensão dos problemas científicos contemporâneos.
\end{abstract}

\section{Metodologia de pesquisa}

Quanto aos fins ou objetivos a pesquisa apresenta características de pesquisa exploratória, e quanto à abordagem ou objeto, como bibliográfica. Tratase de pesquisa exploratória, inicialmente, visando a subsidiar todos os componentes para a elaboração deste estudo: a definição do objeto, a revisão da literatura, a escolha do referencial teórico e a formulação da metodologia, para, em seguida, proceder-se à investigação de modo mais sistemático e aprofundado (TRIVIÑOS, 1990; MARCONI \& LAKATOS, 1999).

Caracteriza-se como pesquisa bibliográfica, porque tem por finalidade conhecer e divulgar as diferentes formas de contribuição científica sobre o objeto deste trabalho (ANDRADE, 2004; OLIVEIRA, 1999). 


\section{A epistemologia de Gaston Bachelard: uma ruptura com as filosofias do imobilismo}

M.A.M. Lima \& M. Marinelli

\section{Vida e obra de Gaston Bachelard}

Filósofo e ensaísta francês, Bachelard nasceu em Bar-sur-Aube, região da Champaigne Francesa, em 27 de Junho de 1884, e faleceu em Paris em 16 de Outubro de 1962, tendo, portanto, pertencido a dois séculos e vivido a ruptura que marcou tal passagem.

Após concluir o bacharelado em Bar-sur-Aube em 1903, trabalhou nos correios de Remiremont até 1906. Transferiu-se para Paris (1907-1912), licenciando-se em Matemática em 1912. A guerra o impediu de continuar os estudos, pois foi convocado em 1914 para se apresentar ao exército, retornando em 1918. Após a desmobilização, retorna a Bar-sur-Aube, onde lecionou Física e Química no ensino secundário.

A teoria da relatividade deitou por terra as suas ideias no campo da Física, o que o levou a estudar Filosofia, obtendo uma segunda licenciatura em letras em 1920.

Concluiu doutorado na Sorbonne em 1927, com a tese "Ensaio sobre o conhecimento aproximado". Em 1930 iniciou uma carreira regular de professor universitário, lecionando na Faculté des Lettres da Universidade de Dijon (19301940), e na Sorbonne (Paris), onde ensinou História e Filosofia das Ciências, ali permanecendo até 1954. Em 1955 entrou para a Academia das Ciências Morais e Políticas.

Além de filósofo, crítico e epistemólogo, era cientista e poeta e publicou obras que revelaram interesses em Filosofia das Ciências, Lógica, Psicologia e poesia. Seu primeiro livro foi Essai sur la conaissance approchée (1928) e seu livro mais famoso foi Le Nouvel esprit scientifique (1934). Recebeu a Legião de Honra em 1951 e o Grande Prêmio Nacional das Letras (1961). Morreu em Paris, em 1962, deixando uma obra que passou a ser de grande relevância para a compreensão dos problemas científicos contemporâneos (JAPIASSU, 1992; BARBOSA \& BULCÃO, 2004).

Sua vida foi marcada por descontinuidades e rupturas que dinamizaram e enriqueceram as suas obras. A obra de Bachelard pode ser expressa em diurna e noturna, como o próprio autor noticia no seguinte trecho do livro Poética do Espaço (1957): “... tarde demais conheci a tranquilidade de consciência no trabalho alternado das imagens e dos conceitos, duas tranquilidades de consciência que seriam a do pleno dia e a que aceita o lado noturno da alma" (BACHELARD, 1988; p. 52).

Considerando-se estas características de Bachelard, seus analistas passaram a dividir a sua obra em "diurna", aquela que pensa o saber científico, expresso na Epistemologia e na História das Ciências, e de outro lado, a sua obra "noturna", que se debruça sobre a criação artística, e remete ao estudo no âmbito da imaginação poética, dos devaneios e dos sonhos (BARBOSA \& BULCÃO, 2004; JAPIASSÚ, 1992; MARINELLI, 2007). 


\section{HUMANAS}

Ambas vertentes coexistem e se complementam, pois também a ciência requer imaginação e sonho para ir adiante e avançar na construção de novos conhecimentos, assim como a vertente artística necessita do espírito racionalista para compreender de modo imaginativo (SILVA DE SOUZA, 2007).

Dentre as obras diurnas destacam-se: O novo espírito científico (1934), A formação do espírito científico (1938), A filosofia do não (1940), O racionalismo aplicado (1949) e O Materialismo Racional (1952). Já, entre as obras noturnas temos: A psicanálise do fogo (1938); A água e os Sonhos (1942); O ar e os sonhos (1943); A terra e os devaneios da vontade (1948); A poética do espaço (1957).

Pretendemos nos deter na obra diurna de Gaston Bachelard, analisando o potencial metodológico implícito na sua epistemologia.

\section{O surgimento da epistemologia bachelardiana}

A epistemologia bachelardiana surge em meio às revoluções no meio do pensamento científico do final do século XIX e início do século XX, tais como a teoria da relatividade, a física quântica e as geometrias não-euclidianas. Bachelard (1996) afirma que o pensamento científico seria explicado em três grandes momentos: o estado pré-científico, que vai da Antiguidade Clássica até o século XVIII; o estado científico, envolvendo o período do final do século XVIII até o século XX; e o novo espírito científico, a partir das publicações de Einstein, em 1905.

Tais revoluções repercutiram nos vários campos do saber, provocando alterações na compreensão da realidade e nas relações entre sujeito e objeto, o que ocasionaria a elaboração de um novo saber científico. O aparecimento do elemento infinitesimal abala toda uma perspectiva vigente.

Em conseqüência dessas mudanças no mundo da ciência e da necessidade de formas diferenciadas de apreendê-las, surgiram novas questões para a epistemologia, cabendo-lhe construir conceitos para lidar com a perspectiva instaurada por tais teorias, bem como repensar a própria História das Ciências. $\mathrm{O}$ aparecimento de tais teorias apontou a variabilidade da própria racionalidade, tendo em vista que seus princípios não são imutáveis. E é partindo deste objetivo que Bachelard formula suas principais proposições para a Filosofia das Ciências: a historicidade da Epistemologia e a relatividade do objeto. 


\section{A epistemologia de Gaston Bachelard: uma ruptura com as filosofias do imobilismo}

\section{Crítica às filosofias vigentes}

Um dos maiores embates de Bachelard foi justamente com aqueles que defendiam o continuísmo e o imobilismo, ou seja, que defendiam a idéia de que entre a ciência e o senso comum não existe mais que uma diferença de profundidade, portanto, continuidade epistemológica.

Refere-se, muitas vezes, à inadequação destas filosofias, mostrando que estas não conseguiam expressar os novos caminhos que a ciência contemporânea assumira a partir do advento das geometrias não euclidianas, da teoria da relatividade e da mecânica quântica (BARBOSA \& BULCÃO, 2004).

Um dos defensores do continuísmo era o filósofo francês Émile Meyerson ${ }^{3}$, para quem a física relativista se submete ao cânone eterno do intelecto humano, que constitui não somente a ciência, mas, antes dela, o mundo do senso comum. O quadro 1, a seguir, retrata as diferentes abordagens dos dois epistemólogos.

\section{Quadro 1}

Diferenças epistemológicas entre Meyerson e Gaston Bachelard.

\begin{tabular}{|l|l|}
\hline A epistemologia de Émile Meyerson & \multicolumn{1}{|c|}{ A epistemologia de Gaston Bachelard } \\
\hline $\begin{array}{l}\text { Sua obra teve como intuito demonstrar } \\
\text { que a ciência é, em última instância, } \\
\text { ontologia e, nesse sentido, sua } \\
\text { preocupação primordial é de forma } \\
\text { absoluta expressar a natureza. }\end{array}$ & $\begin{array}{l}\text { Desconfiou do caráter ontológico do saber } \\
\text { científico contemporâneo que, em lugar de se } \\
\text { voltar para um real que preexiste ao processo } \\
\text { cognitivo, constrói seu objeto ao longo do ato } \\
\text { de conhecer. }\end{array}$ \\
\hline $\begin{array}{l}\text { Defendeu a idéia de que a física de } \\
\text { Einstein é uma continuação da física } \\
\text { de Newton. }\end{array}$ & $\begin{array}{l}\text { Mostrou que a ciência einsteiniana constituiu } \\
\text { profunda ruptura com a Física e a Mecânica } \\
\text { newtoniana, impondo-se como uma teoria, } \\
\text { cujos princípios são uma retificação dos } \\
\text { princípios da física clássica. }\end{array}$ \\
\hline $\begin{array}{l}\text { A razão se desenvolve a partir de } \\
\text { categorias absolutas, presentes em toda } \\
\text { atividade cognitiva. }\end{array}$ & $\begin{array}{l}\text { A razão é fundamentalmente descontínua } \\
\text { retificando-se em si mesma, a seus métodos e } \\
\text { a seus próprios princípios, o que a torna } \\
\text { dinâmica e inconstante. }\end{array}$ \\
\hline $\begin{array}{l}\text { Há continuidade entre senso } \\
\text { comum e ciência. }\end{array}$ & $\begin{array}{l}\text { Aponta a descontinuidade entre o o } \\
\text { conhecimento científico e o conhecimento } \\
\text { comum, pois a ciência não procede deste } \\
\text { último, mas, ao contrário, se constrói através } \\
\text { da negação da experiência primeira. }\end{array}$ \\
\hline
\end{tabular}

${ }^{3}$ Filósofo francês de origem polonesa (1859-1933). Estudou química na Alemanha e na França, onde se instalou em 1882. Dedicou-se a filosofia das ciências e se opôs a epistemologia positivista. Entre suas obras, cabe citar Identidade e realidade (1907) e Sobre a explicação das ciências (1921). (JAPIASSU; MARCONDES, 2008). 


\section{HUMANAS}

Em Bachelard (2000), o "novo espírito científico" acha-se em descontinuidade, em ruptura com o senso comum, sendo uma marca da teoria bachelardiana.

O espírito científico é essencialmente uma retificação do saber, um alargamento dos quadros do conhecimento. Julga o seu passado condenando-o. A sua estrutura é a consciência dos seus erros históricos. Cientificamente, pensa-se o verdadeiro como retificação histórica de um longo erro, pensase a experiência como retificação da ilusão comum e primeira (BACHELARD, 1996; p. 120).

Bachelard apresenta, também, críticas à doutrina espiritualista de Maine de Biran ${ }^{4}$. Também conhecido como espiritualismo eclético. Este fenômeno ocorreu na França, no século XIX, tendo como expoentes Maine de Biran e Victor Cousin (1792-1867). A doutrina espiritualista desenvolveu-se, principalmente, nos círculos católicos e mesmo cristãos em geral, apresentando característica, ao mesmo tempo, realista e espiritualista.

Quadro 2

Diferenças epistemológicas entre Maine de Biran e Gaston Bachelard.

\begin{tabular}{|l|l|}
\hline \multicolumn{1}{|c|}{ O espiritualismo de Maine de Biran } & \multicolumn{1}{|c|}{$\begin{array}{c}\text { A epistemologia de Gaston } \\
\text { Bachelard }\end{array}$} \\
\hline $\begin{array}{l}\text { Era uma doutrina que se impunha como forma de } \\
\text { idealismo. Exaltava os valores morais, a liberdade } \\
\text { humana e, sobretudo, a liberdade do espírito humano, } \\
\text { procurando encontrar no ato da consciência um acesso ao } \\
\text { absoluto. Era, pois, uma celebração à criação espiritual, } \\
\text { fosse ela científica, estética, moral ou religiosa. }\end{array}$ & $\begin{array}{l}\text { Se insurge contra os } \\
\text { pressupostos metafísicos e } \\
\text { idealistas. }\end{array}$ \\
\hline $\begin{array}{l}\text { Centrava o seu objetivo na apreensão de si mesmo, } \\
\text { acreditando que se podia chegar ao conhecimento do } \\
\text { universo a partir da intuição e da experiência cotidiana. }\end{array}$ & $\begin{array}{l}\text { A razão tem uma história e } \\
\text { essa história é uma } \\
\text { demonstração de que sua } \\
\text { trajetória é descontínua e } \\
\text { plena de obstáculos. }\end{array}$ \\
\hline $\begin{array}{l}\text { Reforçava as teses metafísicas, não se dedicando à } \\
\text { reflexão da ciência e de seus pressupostos que podiam } \\
\text { ser compreendidos a partir dos a priori da razão, isto é, } \\
\text { faziam parte do esquema (transcendental) de organização } \\
\text { do conhecimento. }\end{array}$ & $\begin{array}{l}\text { Somente uma epistemologia } \\
\text { que parta da reflexão da } \\
\text { própria ciência pode se } \\
\text { tornar adequada para } \\
\text { expressá-la. }\end{array}$ \\
\hline
\end{tabular}

${ }^{4}$ Filósofo francês (1766-1824). Desempenhou na vida política diversos papéis importantes (deputado e conselheiro de Estado). Influenciou a reação espiritualista que marcou a filosofia francesa no início do século XIX. A oposição entre o sentimento e a reflexão, entre a passividade e a atividade, são os temas principais de Maine de Biran. Seu trabalho filosófico foi realizado na forma de memórias, reflexões e diário. Foi autor das obras: A influência do hábito (1802), A decomposição do pensamento (1805), Relações entre o físico e o moral (1814) e Diário íntimo (1927) (JAPIASSU \& MARCONDES, 2008). 


\section{A epistemologia de Gaston Bachelard: uma ruptura com as filosofias do imobilismo}

O espiritualismo se posicionava contra o idealismo, e também, contra o positivismo e o materialismo, bem como contra os monismos de qualquer espécie (BARBOSA \& BULCÃO, 2004; JAPIASSÚ, 1976). No quadro 2 estão descritas as diferentes visões de Maine de Biran e de Gaston Bachelard.

Bachelard se insurge contra os pressupostos metafísicos e idealistas que sustentavam a doutrina do espiritualismo, asseverando que o conhecimento se constrói por um rompimento com o conhecimento comum e com a intuição imediata, realçando a importância do trabalho cuidadoso do cientista (BACHELARD, 1972; 2000).

Posiciona-se, ainda, contra o positivismo de Auguste Comte ${ }^{5}$. O positivismo surge no século XIX, junto com as transformações sociais e econômicas, políticas, ideológicas, tecnológicas e científicas decorrentes do nascimento da sociedade industriale da consolidação do capitalismo.

Quadro3

Diferenças epistemológicas entre Auguste Comte e Gaston Bachelard.

\begin{tabular}{|c|c|}
\hline O positivismo de Auguste Comte & A epistemologia de Gaston Bachelard \\
\hline $\begin{array}{l}\text { Aplicação de esquemas gerais aos fatos } \\
\text { empíricos observados, caminhando-se, } \\
\text { assim, da experiência para a teoria que } \\
\text { a explicita. Só se pode estar seguro de } \\
\text { sua abstração quando esta se refere a } \\
\text { fatos experimentais. }\end{array}$ & $\begin{array}{l}\text { O estado abstrato, ao contrário, polemiza a } \\
\text { experiência, caracterizando-se pela } \\
\text { construção de esquemas racionais cada vez } \\
\text { mais abstratos e afastados do empírico. }\end{array}$ \\
\hline $\begin{array}{l}\text { A observação dos fatos é a única base } \\
\text { sólida dos conhecimentos humanos. } \\
\text { Consiste na descrição das relações } \\
\text { exatas entre os fatos observados. }\end{array}$ & $\begin{array}{l}\text { Não tem sentido se falar de fenômenos } \\
\text { naturais, pois a ciência contemporânea } \\
\text { instaura o homem em um mundo novo, no } \\
\text { qual a racionalidade é produtora de } \\
\text { descobrimentos e no qual o objeto passa a ser } \\
\text { um resultado do próprio ato de conhecimento. }\end{array}$ \\
\hline O objeto é dado pela ciência. & $\begin{array}{l}\text { O objeto científico deixa de ser o dado para } \\
\text { ser o resultado de elaborações teóricas e } \\
\text { experimentais. }\end{array}$ \\
\hline $\begin{array}{l}\text { Pressupõe o progresso contínuo do } \\
\text { saber. A razão segue uma evolução } \\
\text { lenta, através da qual a passagem de um } \\
\text { estado a outro não está sujeita a saltos. }\end{array}$ & $\begin{array}{l}\text { A descontinuidade e a ruptura com o saber } \\
\text { anterior são a mola propulsora do progresso e } \\
\text { do desenvolvimento da razão. }\end{array}$ \\
\hline
\end{tabular}

${ }_{5}^{5}$ Filósofo francês (1798-1857). Viveu numa fase da história francesa em que se alternavam regimes despóticos e revoluções. Este contexto propiciou em Comte um descontentamento geral com a política, bem como a uma crise dos valores tradicionais. Em resposta a esse estado de ânimo, Comte combinou elementos da obra de pensadores anteriores, bem como de alguns contemporâneos, derivando num corpo teórico a que chamou de positivismo. Entre suas obras cabe destacar: Sistema de Filosofia Positiva (1848), Sistema de Politica Positiva (1851-54, quatro volumes) e Síntese Subjetiva (1856) (JAPIASSU; MARCONDES, 2008). 


\title{
HUMANAS
}

A doutrina comteana associa a interpretação das ciências à descrição das relações exatas entre os fatos observados. Afirma que a existência humana está fundada em valores completamente humanos, afastando radicalmente a teologia e a metafísica (BARBOSA \& BULCÃO, 2004; JAPIASSÚ, 1976). No quadro 3 estão expostas as diferentes visões de Auguste Comte e Gaston Bachelard.

O objeto desta nova ciência não é dado pela natureza. É algo constituído pelo sujeito. Se, no positivismo, o sujeito era um mero receptáculo das verdades científicas, o sujeito da ciência contemporânea é quem constrói o objeto científico pela junção que faz entre razão e técnica (BACHELARD, 1996). Em resumo, a nova ciência relativista rompe com as ciências anteriores em termos epistemológicos e a sua metodologia já não pode ser empirista, pois o seu objeto encontra-se em relação, e não é mais absoluto. Nas palavras de Bachelard:

\begin{abstract}
Várias vezes, nos diferentes trabalhos consagrados ao espírito científico, nós tentamos chamar a atenção dos filósofos para o caráter decididamente específico do pensamento e do trabalho da ciência moderna. Pareceu-nos cada vez mais evidente, no decorrer dos nossos estudos, que o espírito científico contemporâneo não podia ser colocado em continuidade com o simples bom senso (BACHELARD, 1972; p. 27).
\end{abstract}

A superação do empirismo, para Bachelard, dá-se através do racionalismo. A sua visão é a de uma interação, ou seja, uma dialética entre razão e experiência, de coisas opostas que se integram no todo. O novo racionalismo admite o diálogo com a experiência. É preciso compreender a reciprocidade das dialéticas que vão, interminavelmente, do espírito às coisas e das coisas ao espírito (BACHELARD, 1977; 2000). Segundo Bachelard (1972), o método científico já não é direto, imediato, mas indireto, mediado pela razão. Assim sendo, o vetor epistemológico, se desloca do racional para o real, diferentemente à epistemologia até então vigente. $\mathrm{O}$ grande marco em relação às ciências anteriores ao século XX é a superação do empirismo pelo racionalismo.

\section{A construção do objeto científico}

A utilização consciente de um método de pesquisa, como a construção do objeto científico, leva o cientista a chegar mais próximo possível da verdade do seu objeto, sem com isso entender o esgotamento do seu estudo, dada a característica dialética da sociedade e do conhecimento. 


\section{A epistemologia de Gaston Bachelard: uma ruptura com as filosofias do imobilismo}

A realidade social, e a educacional mais especificamente, é objeto de avaliação por todos aqueles que vivem na sociedade, o que torna a tarefa do cientista social ainda mais difícil, pois deve construir seu conhecimento apesar e contra o senso comum; apesar e contra a realidade.

Em sua tese de doutoramento, "Ensaio sobre o conhecimento aproximado", publicada em 1927, Bachelard formula a teoria do aproximacionalismo. Nela, o autor retrata que a indefinição do objeto implica um saber provisório, inconcluso, incompatível com certezas estáveis. O conhecimento, por sua vez, seria constituído por meio de aproximações contínuas, viabilizadas, simultaneamente, pelo modelo teórico e pela aplicação técnica (BACHELARD, 2004).

Equaciona a validade de uma ciência que almeja um conhecimento apto a esgotar a natureza do fenômeno. Questiona a viabilidade de um saber que busca dar conta de todo o real, de uma feita que a realidade apresenta sempre uma resistência, denegando-se a um total desnudamento:

\section{[...] A ciência postula comumente uma realidade. De nosso ponto de vista, esta realidade apresenta no seu aspecto desconhecido, inesgotável, um caráter eminentemente próprio que suscita uma busca sem fim. Todo seu ser reside numa resistência ao conhe- cimento. Nós tomamos, portanto, como postulado da nossa epistemologia, o inacabamento fundamen- tal do conhecimento (BACHELARD, 2004; p. 13).}

As verdades instituídas pela ciência não são imutáveis ou absolutas, mas, e, sobretudo, incompletas, devido, em primeiro lugar, ao próprio objeto, que nunca se expõe em sua plenitude, e, em segundo lugar, pela natureza mesma da relação entre o pensamento e o fenômeno (SANTOS, 1999).

A obra de Bachelard revela o esforço de atualizar a Filosofia da Ciência, idealizando a ciência como um constructo processual e inacabado, no qual se aliam e se alternam razão e experiência.

Para Bachelard, a Filosofia da Ciência, em sua visão tradicional, não contemporiza com a intermediação entre a razão e a experiência, entre a teoria e a prática, quando afirma:

Parece-nos, pois, claro que não dispomos de uma filosofia das ciências que nos mostre em que condições, simultaneamente subjetivas e objetivas, os princípios gerais conduzem a resultados particulares, a flutuações diversas, em que condições os resultados particulares sugerem generalizações que os completem, uma dialética que produz novos princípios (BACHELARD, 1991; p. 8). 


\section{HUMMANAS}

Em Bachelard, o pensamento científico moderno não se restringe a citar leis, nem se limita a transcrever as informações colhidas na observação; devese ir além, recriando o real e equacionando a sua própria constituição.

Pensar a atividade científica envolve a interdependência dos extremos. Para os empiristas, a experiência surge uniforme, originando-se nas sensações; para os idealistas, a unidade da experiência emana do fato de serem elas apreendidas pela razão. E no dizer de Bachelard (2000; p. 17):

[...] A partir do momento em que se medita na ação científica, apercebemo-nos de que o realismo e o racionalismo trocam entre si infindavelmente os seus conselhos. Nem um nem outro isoladamente basta para construir a prova científica... Não há lugar para uma intuição do fenômeno que designaria de uma só vez os fundamentos do real, também não há lugar para uma convicção racional - absoluta e definitiva - que imporia categorias fundamentais aos nossos métodos de pesquisas experimentais.

Ao fazer da ciência seu objeto de reflexão, empiristas e racionalistas aludem a uma ciência ideal, diferente daquela praticada concretamente, desconsiderando a sua realidade prática efetiva, amparando-se em processos gerais que, geralmente, não coincidem com a atividade científica.

Sustenta que à epistemologia cabe debruçar-se sobre a prática concreta da ciência, argüindo a constituição do processo de racionalização e os tipos de ocorrência que podem obstaculizar as novas descobertas (BACHELARD, 2000).

Entende que o novo espírito da ciência contemporânea é um pensamento instruído, instrutor e construtor, que se instrui enquanto constrói, sendo uma objetivação que se move a partir das retificações e objetivações. O novo espírito científico representa um pensamento que é um programa de experiências a realizar, estando unido à experiência. Criando seus objetos para pensá-los, é um pensamento criador, dinâmico, que trabalha a retificação e a diversificação, liberando-se da certeza, da unidade e da imobilidade; pensa o antigo em função do novo, numa ruptura com a continuidade, que compreende as noções como movimento do pensamento (BACHELARD, 2000).

\section{Os conceitos da Epistemologia Bachelardiana}

A coerência da epistemologia bachelardiana torna-se mais compreensível a partir do entendimento dos conceitos de ruptura, corte epistemológico, vigilância, obstáculo, problemática e recorrência epistemológica (LIMA, 2008). 


\section{A epistemologia de Gaston Bachelard: uma ruptura com as filosofias do imobilismo}

A ruptura epistemológica pode ser definida como fenômeno que determina o nascimento de uma nova ciência. Diz respeito a um rompimento com o saber passado. Indica uma forma mais científica de produzir ciências; a noção de processo dialético na produção de conhecimento científico e a concepção de conhecimento como progresso contínuo de retificação.

Em outros termos, Bachelard (1977) assevera que a razão não se rege pelos mesmos princípios; mas se reorganiza, para continuar sendo válida. Assim sendo, o progresso é descontínuo, não sendo um acúmulo de conhecimento. A historicidade descontínua é aquela que progride por meio de rupturas. Aceita-se uma teoria hoje, rompe com seus princípios e forma outra amanhã. Não há acúmulo de conhecimentos, assumindo uma postura epistemológica.

Já os cortes epistemológicos são descontinuidades na produção do saber científico. Podem ser entendidos como "ponto de não retorno, o momento a partir do qual uma ciência começa, a partir do qual assume sua história e já não é mais possível uma retomada de noções pertencentes a momentos anteriores" (JAPIASSU \& MARCONDES, 2008; p. 59).

Outro ponto importante para a compreensão do que chamamos metodologia bachelardiana, é a sua noção de obstáculos epistemológicos, tratado, sobretudo, na obra A Formação do Espírito Científico, de 1996. Os obstáculos epistemológicos dizem respeito a preconceitos que impedem e bloqueiam o surgimento do real e de novas ideias, representando um imobilismo da ciência, impedindo o seu progresso (BACHELARD, 1996). Sobre esse aspecto, Bachelard (1971; p. 165) assevera que:

[...] É no âmago do próprio ato de conhecer que aparecem, por uma espécie de imperativo funcional, lentidões e conflitos. É aí que mostraremos causas de estagnação e até de regressão, detectaremos causas de inércia às quais daremos o nome de obstáculos epistemológicos.

Bachelard (1996) enumera alguns tipos de obstáculos epistemológicos: opinião; experiência primeira; obstáculo verbal; o conhecimento unitário e pragmático; obstáculo substancialista; psicanálise do realista; o obstáculo animista; o mito da digestão; libido e conhecimento objetivo; e obstáculos do conhecimento quantitativo.

A noção de obstáculo epistemológico é de fundamental importância para o desenvolvimento do conhecimento no âmbito das pesquisas. É na superação destes obstáculos que reside o sucesso de uma pesquisa científica. Porém, uma condição essencial para a superação dos obstáculos é a consciência, por parte dos cientistas, de que eles existem e que, se não neutralizados, podem comprometer o processo da pesquisa, desde seus fundamentos até os seus resultados. 


\section{HUMANAS}

A problemática é um dos conceitos fundamentais na epistemologia bachelardiana. O pensamento científico começa com um problema, porém esse problema a razão não detecta, a razão o formula. A elaboração da problemática considera a existência de um modelo teórico e técnico, que no percurso da objetivação, dará lugar à novidade simultânea na experiência e no pensamento (BACHELARD, 1977).

Quanto à vigilância, apresenta-se como um comportamento, uma atitude do pesquisador frente ao seu objeto de estudo, exercendo especial atenção em relação à aplicação do método. Ocorre em três graus: a atenção ao inesperado; a vigilância à aplicação do método; e a vigilância sobre o próprio método (BACHELARD, 1977).

A vigilância crítica situa-se tanto na lógica da descoberta, quanto na lógica da prova. Enquanto a descoberta se preocupa com o exame do processo de produção dos objetos científicos, a prova, por outro lado, ocupa-se da análise dos procedimentos lógicos da validação e proposição de critérios de demarcação para as práticas científicas (MARTINS \& THEÓPHILO, 2007).

Assinala, ainda, que a recorrência epistemológica diz respeito às certezas - sempre provisórias - do presente que redefinem o passado, instituindo uma releitura, uma reorganização do antigo (BACHELARD, 2004).

Como visto, a história da ciência altera, permanentemente, os sentidos dos eventos que a compõem, e se configura como resultante da determinação dos sucessivos valores gerados pelo progresso científico.

\section{Considerações finais}

A partir deste estudo esperou-se analisar as idéias centrais da obra epistemológica de Gaston Bachelard, demonstrando que a epistemologia bachelardiana opõe-se aos sistemas de pensamento fechado e dogmático, às filosofias tradicionais, com viés empirista, situando-a como uma ação epistemológica na qual os fatos científicos são conquistas contra as evidências do saber imediato e das pré-noções da filosofia espontânea.

O mundo de Bachelard é o do fazer-ser, o de uma obra em construção é criando, produzindo e retificando que o espírito se aproxima da verdade (JAPIASSU, 1976). Foi possível verificar as diferenças entre algumas epistemologias vigentes à época da elaboração da epistemologia bachelardiana (realismo de Émile Meyerson; doutrina espiritualista de Maine de Biran; e o positivismo de Auguste Comte).

Os diversos conceitos epistemológicos aprimorados por Bachelard, tais como: ruptura, corte epistemológico, vigilância, obstáculo, problemática e recorrência epistemológica, quer sejam discutidas, contestadas ou utilizadas, 
não deixam de estar presentes e atuantes nos debates do meio científico. Assim sendo, fica evidente a contribuição e a importância do legado de Bachelard, servindo de suporte para discussões metodológicas e para uma prática científica aberta, crítica e reflexiva nos diversos campos da ciência.

\section{Referências bibliográficas}

ANDRADE, M.M. Como preparar trabalhos para cursos de pós-graduação. São Paulo: Atlas, 2004.

BACHELARD, G. A epistemologia. São Paulo: Martins Fontes, 1971.

BACHELARD, G. Conhecimento comum e conhecimento científico. Revista Tempo Brasileiro, 28: 47-56, 1972.

BACHELARD, G. O racionalismo aplicado. Rio de Janeiro: Zahar, 1977.

BACHELARD, G. A poética do devaneio. São Paulo: Martins Fontes, 1988.

BACHELARD, G. A filosofia do não. Lisboa: Presença, 1991.

BACHELARD, G. A formação do espírito científico: contribuição para uma psicanálise do conhecimento. Rio de Janeiro: Contraponto, 1996.

BACHELARD, G. O novo espírito científico. Rio de Janeiro: Tempo Brasileiro, 2000.

BACHELARD, G. Ensaio sobre o conhecimento aproximado. Rio de Janeiro: Contraponto, 2004.

BARBOSA, E. \& BULCÃO, M. Bachelard: pedagogia da razão, pedagogia da imaginação. Petrópolis: Vozes, 2004.

JAPIASSÚ, H.F. Para ler Bachelard. Rio de Janeiro: Francisco Alves, 1976.

JAPIASSÚ, H.F. Introdução ao pensamento epistemológico. Rio de Janeiro: Francisco Alves, 1992.

JAPIASSU, H. \& MARCONDES, D. Dicionário básico de filosofia. Rio de Janeiro: Zahar Ed., 2008.

LIMA, M.A.M. Auto-avaliação e desenvolvimento institucional na educação superior: projeto aplicativo em cursos de administração. Fortaleza: Edições UFC, 2008. 


\section{HUMANAS}

MARCONI, M.A. \& LAKATOS, E.M. Técnicas de pesquisa. São Paulo: Atlas, 1999 .

MARINELLI, M. Educação corporativa: um estudo sobre modelos de avaliação de programas. Coleção Temas em Avaliação no 6. Fortaleza: Editora UFC, 2007.

MARTINS, G.A. \& THEÓPHILO, C.R. Metodologia da investigação científica para ciências sociais aplicadas. São Paulo: Atlas, 2007.

OLIVEIRA, S.L. Tratado de metodologia científica: projetos de pesquisas, TGI, TCC, monografias, dissertações e teses. São Paulo: Pioneira, 1999.

SANTOS, B.S. Um discurso sobre as ciências. Lisboa: Afrontamento, 1999.

SILVA DE SOUZA, I.M. Os fundamentos antropofilosóficos da epistemologia de Gaston Bachelard. Tese de Doutoramento. Faculdade de Filosofia. Universidade de Santiago de Compostela, Santiago de Compostela, 2007.

TRIVINÕS, A.N.S. Introdução à pesquisa em ciências sociais: a pesquisa qualitativa em educação. São Paulo: Atlas, 1990. 